\title{
Modifiers of non-specific symptoms in occupational and environmental syndromes
}

\author{
A Spurgeon, D Gompertz, J M Harrington
}

\begin{abstract}
Many occupational and environmental health hazards present as an increased reporting of non-specific symptoms such as headache, backache, eye and respiratory irritation, tiredness, memory problems, and poor concentration. The pattern and number of such symptoms is surprisingly constant from hazard to hazard suggesting that common psychological and social factors, not directly related to the exposure may be involved. A recent workshop (see acknowledgements) was held to review the pattern of symptoms in varying hazardous situations and the psychological mechanisms behind the genesis and maintenance of symptoms. The involvement of both direct physicochemical and psychological mechanisms in symptom generation and reporting in any situation was discussed and is reported here. A model that identifies the issues that need to be considered in any epidemiological study based on the incidence or prevalence of non-specific symptoms is proposed.
\end{abstract}

Institute of
Occupational Health,

University of

Birmingham,

Edgbaston,

Birmingham

A Spurgeon

D Gompertz

J M Harrington

Correspondence to:

Dr A Spurgeon, Institute of

Occupational Health,

Uccupational Health,

Edgbaston, Birmingham

Edgbaston, Birming
BT15 2TT, UK.

Accepted 16 January 1996

(Occup Environ Med 1996;53:361-366)

Keywords: hazard; symptoms; psychological factors; stress

Several occupational and environmental health concerns which have attracted considerable publicity in recent years have been characterised by an increase in the number and severity of a range of non-specific symptoms. These symptoms include headache, backache, eye

Symptoms typically reported in relation to different hazards and in the general population

\begin{tabular}{|c|c|c|c|c|c|c|c|}
\hline Symptom & Camelford & Braer & $S B S$ & $V D T s$ & $E M F s$ & OPs & $\begin{array}{l}\text { General } \\
\text { Population }\end{array}$ \\
\hline Headache & & $\star$ & $\star$ & $\star$ & $\star$ & $\star$ & * \\
\hline Eye irritation & $\star$ & $\star$ & * & * & & $\star$ & * \\
\hline Sore throat & * & * & * & & & * & * \\
\hline Nasal symptoms & & * & * & & & $\star$ & * \\
\hline Cough & & & * & & & * & * \\
\hline Fatigue & * & & $\star$ & * & $\star$ & $\star$ & * \\
\hline $\begin{array}{l}\text { Memory concentration } \\
\text { difficulties }\end{array}$ & $\star$ & & & & * & * & \\
\hline Gastrointestinal disturbance & * & * & * & & * & * & 夫 \\
\hline Backache & & & * & * & & & 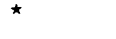 \\
\hline $\begin{array}{l}\text { Other musculoskeletal } \\
\text { problems }\end{array}$ & * & & * & $\star$ & & & $\star$ \\
\hline Anxiety & * & & & * & $\star$ & $\star$ & * \\
\hline Depressed mood & * & & * & & * & $\star$ & * \\
\hline Skin rash or irritation & * & & * & * & & $\star$ & * \\
\hline
\end{tabular}

Camelford, accidental contamination of drinking water with aluminum sulphate ${ }^{13}$; Braer, contamination of an island community with tanker oil ${ }^{267}$; SBS, "sick building syndrome" ${ }^{9}$; VDTs, video display terminals $s^{18}$; EMFs, electromagnetic fields ${ }^{24}$; OPs, organophosphorus pesticides $^{27-29}$; General population, various studies ${ }^{16174143}$;

See text for more details of individual studies. irritation, nasal congestion, tiredness, memory problems, and poor concentration. Several occupational health issues which have been treated as independent problems and investigated in separate epidemiological exercises seem to be associated with a similar pattern of symptom reporting. Furthermore, the total number of individual symptoms seem to remain fairly stable, although the pattern may vary according to the hazard and the time relative to the exposure. These points may be illustrated by examples drawn from several studies relating either to a specific episode where toxic exposure was suspected, or to the investigation of a long term occupational or environmental hazard (table).

Examples of specific incidents in the United Kingdom include a water poisoning accident in Camelford, Cornwall ${ }^{1}$ and the sinking of the Braer oil tanker off the Scottish coast which resulted in oil vapour being blown over the land. ${ }^{2}$ In the case of Camelford the water supply was accidentally contaminated with aluminium sulphate. Residents reported symptoms immediately after the incident which included fatigue, skin rashes, gastrointestinal problems, and joint pain. ${ }^{1}$ In some people complaints of continuing fatigue, anxiety, depressed mood, joint pain, and cognitive difficulties such as memory and concentration problems have persisted. ${ }^{3}$ Two separate enquiries into the incident, however, ${ }^{45}$ came to the conclusion that it was not possible to identify a definite link between the chronic symptoms reported and the ingestion of the aluminium sulphate. Despite this, health concerns (symptoms) and general anxiety among sections of the community have continued leading some to suggest that alleged misinformation provided by the water company at an early stage and a subsequent failure of the authorities to carry out a timely, systematic and coordinated investigation into the problem may have contributed significantly to this situation. In the Braer incident an oil tanker ran aground in bad weather off the coast of Scotland, leaking its cargo of crude oil exposing sections of the population to oil vapour. Immediately after the incident there was an increased level of symptoms reported including headache and eye and throat irritation. ${ }^{6}$ However, unlike those symptoms reported in Camelford, complaints did not seem to persist at a six month follow up. ${ }^{7}$ Here the suggestion has been made that better management of the situation, fostering better public relations and confidence in the relevant authorities contributed to a reduction in anxiety which in turn 
reduced the symptoms reported. The interpretation of the differing results of these incidents indicates that social and psychological factors may have an important part to play, particularly in relation to long term outcomes.

In the field of occupational health, non-specific symptoms have been recorded in relation to a variety of long term hazards. For example, during the 1970s the term "sick building syndrome" (SBS) was created to describe a range of symptoms frequently reported by office workers. These symptoms mainly comprised headache and fatigue, concentration difficulties, mood disturbance, gastrointestinal problems and eye, skin, and upper airway irritation. ${ }^{8}$ Similar symptoms were identified in a large scale investigation of the health of civil servants employed in London office buildings. ${ }^{9}$

Several studies have attempted to investigate the relation between SBS symptoms and various aspects of the physical building. ${ }^{1011}$ In the course of these investigations, however, it has become clear that reference to physical factors cannot fully explain the variance in symptom reporting. More recent investigations ${ }^{12} 13$ have highlighted the importance of both demographic and psychosocial factors in the reporting of SBS. For example, most data suggest that women report more symptoms than men $^{14} 15$ and that there is a strong relation between the psychosocial work environment and SBS symptoms. ${ }^{16} \mathrm{~A}$ recent study carried out in the United States concluded that health symptoms were also frequent in non-problem buildings and seem to be related to workers overall perceptions of, and satisfaction with, the work environment. ${ }^{17}$

One potential source of SBS symptoms was originally identified as being the use of visual display terminals (VDTs). Concern about the health effects of VDTs has subsequently developed into a major area of hazard investigation in its own right. The particular focus of health concern seems to vary over time and between cultures, ${ }^{18}$ and includes anxieties about musculoskeletal difficulties and adverse reproductive outcomes. Also a consistent feature of the complaints of VDT users is the frequency of reporting of acute symptoms of headache, fatigue, eye and skin irritation, and general discomfort. ${ }^{19}$ Although there is some evidence that certain people may be neurologically susceptible to such effects as a result of flicker on the VDT screen, ${ }^{20}$ this is unlikely to account for the number of reports of such symptoms among office populations. Added to this, there is an emerging literature on the relation between psychosocial factors and the development of musculoskeletal problems ${ }^{2122}$ which suggests that at least some of the problems directly attributed to use of VDTs may be mediated by psychosocial mechanisms.

The above examples are primarily, although not exclusively, of occupational concern. Others may be drawn from the literature on environmental hazards. Several investigations have been conducted into the supposed hazard to health created by electromagnetic fields, (EMFs). Concern has centred on the potential of EMFs to cause certain cancers. ${ }^{23}$ However, alongside this, studies have also shown that those who live in close proximity to overhead power lines report a range of non-specific symptoms which include general malaise, fatigue, headache, palpitations, and poor appetite. $^{24}$

Toxic waste disposal sites may frequently be situated near residential areas or where reclaimed land has been used for housing development. Such sites tend to generate considerable anxiety in the communities involved. Nearby residents often complain of respiratory problems but also report a range of nonspecific symptoms such as skin irritation, headache, fatigue, and depressed mood. However, increase in these symptoms, compared with control communities, has been noted where the monitoring of levels of exposure to toxic substances has subsequently indicated no hazard to health. ${ }^{25}$

Some hazards have become the focus of both occupational and environmental concern as exposure may occur in both contexts. An example is that of pesticides based on organophosphorous (OPs) which may present a health hazard to agricultural workers during their application and to the community at large as a result of overspraying or persisting residues. A wide range of symptoms have been reported after both short and long term exposure to OPs. Although in some cases these symptoms are consistent with the documented acute physiological effects of short term exposure (related to an inhibition of acetylcholinesterase activity in the nervous system), ${ }^{26}$ they are frequently non-specific in nature and similar to those already reported in relation to other hazards..$^{27}$ In particular chronic effects, reported after long term exposure, tend to focus on cognitive types of symptoms such as confusion, memory loss, and concentration difficulties as well as excessive fatigue, and depressed mood. ${ }^{29}$ Reference to the health effects of exposure to OPs highlights the need to distinguish between acute and chronic effects associated with a particular hazard and between chronic effects which may result from long term exposure and those which constitute long term effects of a single short term incident. Different biological and psychosocial mechanisms may operate in each case.

These various examples indicate that potential hazards to health, differing widely in terms of their physical nature or chemical composition, may result in the reporting of a fairly consistent pattern of a relatively limited group of non-specific symptoms. This may not always be immediately obvious to investigators, concerned as they tend to be with a particular hazard and often unaware of data relating to other seemingly unrelated areas of investigation. Non-specific symptoms are often difficult to explain by direct reference to the exposure in question. In recent years occupational and environmental health seems to be moving away from the study of diseases with well established pathology towards the investigation of exposures associated with less specific symptoms. As a consequence there is a need to develop an approach which takes into account factors 
other than exposure which may influence the expression, amplification, and maintenance of symptom reporting.

\section{Psychosocial factors in symptom reporting}

Considerable attention has been paid in the psychological literature to the role of psychosocial factors in the expression of ill health. ${ }^{30}$ For example, this has been explored in relation to the occurrence of mass psychogenic illness ${ }^{31}$ and individual multiple chemical sensitivity. ${ }^{32}$ Several theoretical approaches have been proposed which consider the way in which individual people perceive events in their external environment and which may therefore have relevance to the question of symptom reporting. ${ }^{30}$ In particular the probability of a person taking note of external stimuli (and presumably also internal stimuli such as symptoms of ill health) and the way in which the information is interpreted, is determined by the context of the event and by reference to what are termed the person's "schemas". ${ }^{33}$ These schemas are habitual ways of thinking about the world and reflect the person's knowledge, attitudes, and beliefs, which are derived from several sources including the attitudes and behaviour of others.

Information from clinical studies has shown that patients' attitudes and beliefs about their illness have a bearing on the symptoms they report and also on their behaviour. In the area of respiratory medicine, for example, symptom reporting has been shown to be more strongly related to aggregate measures of general health perception such as the Sickness Impact Profile than with the state of physical health as more objectively measured by lung function tests. ${ }^{34}$ Also, studies have shown that exercise capacity, as measured by six or 12 minute walking distance, is highly correlated with mood and with attitudes and beliefs about illness and the value of treatment. ${ }^{35}$ These factors seem to be much better predictors of exercise capacity than are measures of lung function. ${ }^{35} 36$

The context in which an event occurs exerts an influence on its perceived importance relative to other stimuli. Further, this importance may be increased by stress. For example, the results of a study of smelter and mine workers who thought their jobs were dissatisfying and uninteresting showed that these workers overreported respiratory symptoms in relation to the results of lung function tests. ${ }^{37}$ Similarly several investigations carried out in Norway have highlighted a strong relation between the development and reporting of muscle pain and psychosocial aspects of the working environment. $^{2138}$ The results of a recent study in Finland ${ }^{39}$ supported these findings and also indicated that psychosocial factors predicted the change in occurrence of musculoskeletal disorders where other factors-namely age, sex, social class, and physical workload were taken into account.

In particular, the presence of work stressors such as high demands associated with limited control and also lack of social support ${ }^{40}$ seem to be associated with an increase in the level of reporting of musculoskeletal problems. Ursin and colleagues ${ }^{41}$ suggest that stress may reduce effective coping behaviour and induce feelings of helplessness which in turn lead to both an increase in muscle tension and an increased tendency to report symptoms. The development of pain is therefore viewed as multicausal resulting from an interaction between physical and psychological factors.

The importance of context, knowledge, and attitudes has also been shown in relation to the perception of risk. Nurses' reported anxiety about the hazards of HIV and hepatitis B virus has been shown to vary according to the context (general as opposed to occupational), and the accuracy of their knowledge about these hazards. ${ }^{42}$

A further approach to the study of symptom reporting involves the examination of certain personality characteristics and behaviour patterns which may predispose a person to perceive or report ill health. Studies carried out in the general population have shown a relation between poor mental health and increased non-specific symptoms. ${ }^{43}$

Several factors relating to aspects of mood disposition have been explored in the psychological literature. Those which seem to have particular relevance in this context (for example the well established traits of anxiety and neuroticism) have, in recent years, been associated with a concept which has been termed "negative affectivity". ${ }^{44}$

Negative affectivity refers to a personality dimension which reflects the experience of negative emotions and negative self concept. Those people who score highly on a scale of negative affectivity, compared with those with low scores, are more likely to express distress and dissatisfaction and to focus on their failures and the negative side of the world in general. Several studies have shown a relation between high negative affectivity and increased reporting of physical and mental symptoms. ${ }^{45-47}$

Moyle $^{48}$ notes that negative affectivity may operate in several ways simultaneously to increase symptom reporting. Most obviously it may simply exert a direct influence on the tendency to report symptoms. Alternatively it may act indirectly, either by influencing a person's perception of the environment or because people with high negative affectivity are more vulnerable to environmental stressors. It is difficult to decide therefore whether people with high negative affectivity actually experience poorer health or simply report more distress.

A person's behaviour pattern which has long been linked to individual perception of health status is that which is termed locus of control. This refers to a person's belief that life events are internally or externally controlled. Originally developed by Rotter ${ }^{49}$ this concept has been extended to include the more specific "health" locus of control, ${ }^{50}$ which refers to people's beliefs about their level of control over the state of their health. For example, people with a high internal locus of control are more likely to 
carry out preventive health measures, to avoid health threatening behaviour, and to have more extensive knowledge about disease. ${ }^{50-52}$ Personal beliefs about control and negative affectivity represent just two potential influences on the level of symptom reporting. Several others have been explored, for example hardiness ${ }^{53}$ and self efficacy ${ }^{54}$ which may also merit investigation in an epidemiological context. Finally, there is evidence to suggest that an increase in general symptom reporting occurs in people who have previously experienced a traumatic life event. ${ }^{30}$ In particular this seems to occur where the event in question has been suppressed rather than discussed. Pennebaker ${ }^{30}$ suggests several possible hypotheses to explain why previous trauma may increase symptom reporting. For example, the event may result in long term stress which in turn results in changes in autonomic and immune function. Alternatively symptom reporting may serve to distract from or suppress thoughts relating to the trauma. Indirectly it may also represent a way of seeking help. Although these alternative hypotheses await investigation, evidence for the relation between previous trauma and increase of symptom reporting seems convincing and constitutes a further aspect of the complex relations involved in this issue.

As well as psychogenic factors certain social mechanisms are invariably involved in the generation and reinforcement of health concerns at group level particularly where a specific hazard is involved. These include the influence and perceptions of health professionals, and issues generated by the media and by the involvement of the legal system. Within these broad categories several factors may operate to enhance general public concern about particular issues and to encourage the formation of pressure groups. For example, a lack of scientific knowledge or a lack of consensus on the interpretation of scientific data, coupled with partial information or propaganda provided by those with vested interests seem to be potent forces. Where the putative victims of a hazard or incident belong either to the more articulate sections of society or to a recognisably vulnerable group such as children, demands for action are likely to be more insistent. ${ }^{55}$ The role of the popular press is central to the process in that it acts both to sensitise the audience and subsequently to report audience reaction to this sensitisation, which may reinforce concern and subsequent symptom reporting.

\section{Towards a future approach}

Some of the factors we have outlined show how the examination of a variety of psychosocial processes is important to an overall understanding of the generation of symptoms in any population exposed to an occupational or environmental hazard. Although these seem to have been extensively studied and documented in other areas of enquiry, notably psychology and sociology, their impact on epidemiological investigation has so far been limited. To enable investigators in the future to make more mean- ingful interpretations of their data there is a need to incorporate such processes into an approach which will be generally applicable to hazard investigation.

$\operatorname{Cox}^{56}$ has described the relation between hazard and health in terms of the interaction between two separate pathways, the direct physicochemical pathway and the indirect psychophysiological pathway. In the physicochemical pathway the hazard may have a direct specific effect on health, whereas in the psychophysiological pathway effects are mediated by anxiety and stress and may be manifested in non-specific symptoms.

These two systems may interact in that the experience of anxiety and stress may alter the response to the hazard in terms either of the physiological effects of exposure or the experience and subsequent symptom reporting. Several psychophysiological and epidemiological investigations in recent years have considered the question of the relation between the psychological experience of stress, resultant physiological responses, ${ }^{57}$ and long term health effects such as cardiovascular disease ${ }^{58}$ and certain forms of cancer. ${ }^{59}$ Similarly the physical state of the person may determine the level of the response to stress as well as affect the direct response to the physical hazard.

We suggest an expanded model that offers a basis for an approach to epidemiological investigation which takes account of factors that may moderate the relation between exposure and symptom reporting. Some of these factors have been highlighted in previous sections, notably the role of individual personality traits and cognitive structures, together with the influence of the social and cultural context in which exposure occurs (figure).

The model indicates five broad areas where information is required to allow proper interpretation of symptom data in hazard epidemiology-namely: (a) knowledge and attitude systems, $(b)$ current levels of stress, $(c)$ preexisting personality factors and behaviour patterns, (d) pre-existing distress from traumatic life events, $(e)$ group based sociological influences occurring in relation to the particular hazard. The tools for measurement of these factors are largely available in the psychological and sociological literature which offers the opportunity to incorporate them into future studies of the health effects of specific hazards.

As well as these, a comprehensive epidemiological approach would also be aided by knowledge of the level of pre-existing symptoms in the general population to identify any real increase associated with exposure. Information relating to this may already be available in a form which can be adapted to provide normative data on the distribution of symptoms in a given sample. This information has either been gathered specifically with the objective of assessing background levels of symptoms or, more commonly, has been obtained from control groups in studies of specific hazards. In the first category for example, a study was carried out in Sweden to assess the prevalence of SBS symptoms in the general population and to attempt to identify environmental, occupa- 


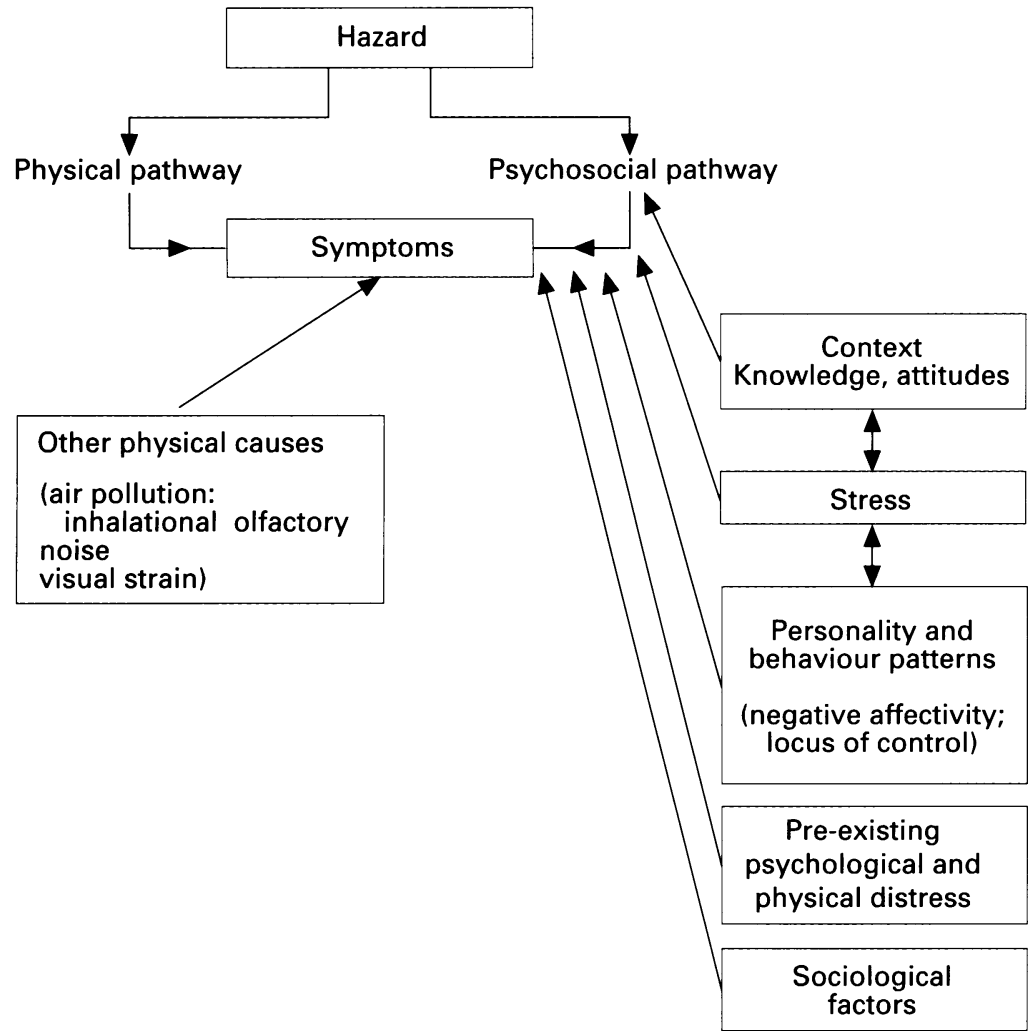

Pathways from hazard to symptoms.

tional, and personal factors associated with an increase in such symptoms. ${ }^{16}$ The results of the study carried out among a random $1 \%$ sample of a Swedish population indicated that such symptoms were extremely common in the general population and seemed to be multifactorial in origin. Ursin and colleagues ${ }^{21}$ investigated the frequency of muscle pain in a sample of healthy workers in Norway and found that $54 \%$ of the women and $40 \%$ of the men reported having experienced muscle pain in the back, neck, or shoulders during the past month.

A study aimed at measuring the prevalence of fatigue in the general population and exploring the factors associated with this was carried out in the United Kingdom. ${ }^{43}$ The results indicated that fatigue was a common symptom in the community with $18 \%$ of respondents complaining of excessive fatigue lasting for more than six months. Finally, a body of data has been gathered in several investigations which used the General Health Questionnaire ${ }^{60}$ a valid and well accepted instrument, which allows comparisons to be made across different occupational and community based groups.

These data, together with those obtained from control groups in many hazard investigations, may provide a basis for compiling information on the background prevalence of symptoms in the general population. Certain difficulties are inherent in this approach as the particular pattern of symptoms in any given sample may depend upon context. However, work carried out by Cox and associates during the 1980 s suggested that an underlying structure of non-specific symptoms can be identified. Psychometric studies on samples of the United Kingdom population, which were subsequently extended to populations in Australia, showed that symptoms of ill health tended to cluster around two factors. The first was defined by symptoms relating to tiredness, cognitive confusion, and emotional lability, (labelled "worn out"). The second was related to worry, fear, tension, and physical signs of anxiety, (labelled "up-tight and tense) ${ }^{61}$ These two factors may correspond to those conditions defined clinically as depression and anxiety. The successful development of a reliable scale of this type indicates that it may be possible similarly to structure other existing data on non-specific symptoms of ill health to provide a means of developing generally applicable background prevalences.

\section{Conclusions and recommendations}

The health outcomes of epidemiological studies of occupational or environmental hazards are frequently characterised by an increase in the reporting of non-specific symptoms which are normally present at some level in unexposed populations and may not be directly and mechanistically related to the specific exposure. To interpret these increases it is necessary to have an understanding of all the factors and mechanisms involved in the generation, amplification, and presentation of such symptoms. An initial model has been proposed here which attempts to describe these factors. We would suggest that this has several implications for future epidemiological research.

(1) Studies of hazard epidemiology dependent on symptom reporting should include measures of relevant individual and social factors to allow the investigator to distinguish symptoms which represent a direct effect of exposure on health and those which are moderated by psychosocial factors.

(2) Investigators could usefully draw on the existing body of psychological and sociological literature both to expand and refine the theoretical basis for symptom generation in hazard investigation and to identify appropriate methodology for future studies.

(3) Consideration should be given to the examination of existing baseline data on non-specific symptoms in the general population which is available from several sources. Discussion among those with experience in this area may result in the development of an approach whereby these and future data may be used to provide background prevalence information, against which real increases in response to specific exposures may be assessed.

A better understanding of the mechanisms involved in the initial production of nonspecific symptoms and the maintenance of their reporting is important not only for the epidemiological assessment of the effects of exposure to occupational and environmental hazards at group level but also for the subsequent management and support of the people involved.

We thank those participants who contributed to the research workshop held in the Institute of Occupational Health, University of Birmingham on 1 November 1994 sponsored by 
the Health and Safety Executive. The support from Professors $M$ Marmot and T Cox during the planning stages is gratefully acknowledged as is that from Dr Paul Davies (HSE). The contributors to the workshop included: Dr D Campbell, Professor T Cox, Professor M Marmot, Dr T McMillan, Professor A J Newman Taylor, Dr D Norback, Dr A Wilkins, Mr B Pearce, Dr S Wessely. The views presented here are ours and do not necessarily reflect those of the Health and Safety Executive nor necessarily reflect those of the Hearticipants of the Workshop.
the partiction

1 Rowland A, Grainger R, Stanwell-Smith R, Hicks N, Hughes A. Water contamination in north Cornwall: a retrospective cohort study into the acute and short-term effects of the aluminium sulphate incident in July 1988. 7 $R$ Soc Health 1990;110:166-72.

2 Campbell DM. The Braer oil spill incident-public health aspects. Health Hygiene 1994;15:139-45.

3 McMillan TM, Freemont AJ, Herxheimer A, Denton J, Taylor AP, Pazianas M, et al. Camelford water poisoning accident: serial neuropsychological assessments and further observation

4 Lowermoor Incident Health Advisory Group (Chairperson: Professor Dame Barbara Clayton). Report on water pollution at Lowermoor, north Cornwall, fuly 1989. London HMSO, 1989.

5 Lowermoor Incident Health Advisory Group (Chairperson: Professor Dame Barbara Clayton). Second report on water pollution

6 Campbell D, Cox D, Crum J, Foster K, Christie P, Brewster D. Initial effects of the grounding of the tanker Braer on health in Shetland. BMF 1993;307:1251-5.

7 Campbell D, Cox D, Crum J, Foster K, Riley A. Later effects of the grounding of tanker Braer on health in Shetland. $B M F$ 1994;309:773-4.

8 Burge S, Hedge A, Wilson S, Bass JH, Robertson A. Sick building syndrome: a study of 4373 office workers. Ann Occup Hyg 1987;31:493-504.

9 Marmot MG, Davey Smith G, Stansfield S, Patel C, North $\mathrm{F}$, Head J, et al. Inequalities in health 20 years on: the Whitehall II study of British civil servants. Lancet 1991; 337:1387-93.

10 Franck C. Eye symptoms and signs in buildings with indoor climate problems (office eye syndrome). Acta Opthalmol (Copenh) 1986;64:306-11.

11 Jaakola JJK, Heinonen OP, Seppalanen O. Sick building syndrome, a sensation of dryness and thermal comfort in relation to room temperature in an office building - need for individual control of temperature. Environment International 1989;15:163-8.

12 Norback D, Michel I, Widstrom J. Indoor air quality and personal factors related to the sick building syndrome. Scand 7 Work Environ Health 1990;16:121-8.

13 Wahlstedt KGI, Edling C. Psychosocial factors and psychosomatic complaints among postal workers. European fournal of Public Health 1994;4:60-4.

14 Skov P, Vallojorn O, Pedersen BV. Influence of personal characteristics, job-related factors and psychosocial fac-
tors on sick building syndrome. Scand $¥$ Work Environ tors on sick building synd
Health $1989 ; 15: 286-95$.

15 Stenberg B, Hansson MK, Sandstrom M, Sundell J, Wall S. A prevalence study of the sick building syndrome (SBS) and facial skin symptoms in office workers. Indoor Air 1993;3:71-81.

16 Norback D, Edling C. Environmental, occupational, and personal factors related to the prevalence of sick building syndrome in the general population. $\mathrm{Br} F$ Ind Med 1991; 48:451-62.

17 Nelson NA, Kaufman JD, Burt J, Karr C. Health symptoms and the work environment in four non-problem United States office buildings. Scand $\mathcal{f}$ Work Environ Health States office

18 Pearce BG. Health hazards and VDTs. Chichester: Wiley, 1984.

19 Finnegan MJ, Pickering CAC, Burge PS. The sick building syndrome prevalence studies. BMF 1984;289:1573-5.

20 Wilkins AJ. Visual distress in the office environment. Facilities 1988;6:9-12.

21 Ursin H, Endresen I, Ursin G. Psychological factors and self-reports of muscle strain. Eur $\mathcal{F}$ Appl Physiol 1988; 57:282-90.

22 Houtman ILD, Bongers PM, Smulders PGW, Kompier M Psychosocial stressors at work and musculoskeletal probPsychosocial stressors at work and musculoskeletal prob-
lems. Scand $₹$ Work Environ Health 1994;20:139-145.

23 NRPB. Supplementary report of an advisory group on nonionising radiation. (Chairperson Sir Richard Doll) Electromagnetic fields and the risk of cancer. 1994;5:79-81.

24 Gamberale F. Physiological and psychological effects of exposure to extremely low frequency electric and magnetic fields on humans. Scand $\mathcal{f}$ Work Environ Health 1990;16(suppl1):51-4.

25 Roht LH, Vernon SW, Weir FW, Pier SM, Sullivan P, Reed LJ. Community exposure to hazardous waste disposal sites: assessing reporting bias. Am $\mathcal{f}$ Epidemiol 1985; 122:418-24

26 Brown SK, Ames RG, Mengle DC. Occupational Illness from cholinesterase inhibiting pesticides among agricultural applicators in California 1982-5. Arch Environ Health 1989;44:34-9.

27 Whorton MD, Obrinsky DL. Persistence of symptoms after mild to moderate acute organophosphate poisoning among 19 farm field workers. F Toxicol Environ Health 1983;1:347-54.

28 Bwititi T, Chilkuni O, Loewenson R, Murambiwa W,
Nhachi C, Nyazema N. Health hazards of organophosphorus use among farm workers in the large scale farming sector. Cent Afr f Med 1987;3:120-6.

29 Stephens R, Spurgeon A, Beach J, Calvert I, Berry H, Levy L. An investigation into the possible chronic neuropsychological and neurological effects of occupational exposure to organophosphates in sheep farmers. Sudbury: HSE Books, 1995. (HSE Contract Research Report No 74.

30 Pennebaker JW. Psychological bases of symptom reporting: perceptual and emotional aspects of chemical sensitivity. Toxicol Ind Health 1994;10:497-511.

31 Colligan MJ, Pennebaker JW, Murphy LR, eds. Mass psychogenic illnes: a social psychological analysis. Jillsdale, NL Erlbaum, 1982

32 Sparks PJ, Daniell W, Black DW, Kipen HM, Alman C, Simon GE, et al . Multiple chemical sensitivity syndrome: a clinical perspective. $\mathcal{F}$ Occup Med 1994;36:718-37.

33 Hastie $R$. Schematic principles in human memory. In Higgins ET, Harman CP, Zanna MP, eds. Social cognition: the Ontario symposium. Hillsdale, NJ: Erlbaum, 1981:1.

34 Jones PW, Baveystock CM, Lillejohn P. Relationships between general health measured with the sickness impact profile and respiratory symptoms, physiological measures, and mood in patients with chronic airflow limitation. $\mathrm{Am}$ Rev Respir Dis 1989;140:1538-43.

35 Morgan AD, Peck DF, Buchanan DR, McHardy GJR Effects of attitudes and beliefs in exercise tolerance in chronic bronchitis. BMf 1983;286:171-3.

36 McGavin CR, Artvinpi M, Naoe H, McHardy GTR Dyspnoea, disability, and distance walked: comparison of estimates of exercise performance in respiratory disease. BMF 1978;2:241-3.

37 Wright D, Kane R, Olsen D, Smith $T$. The effects of selected psychosocial factors on the self-reporting of pulmonary symptoms. $f$ Chron Dis 1977 30:195-206

38 Rimehang T, Svebak S. Psychogenic muscle tension: the significance of motivation and negative affect in percep-
tual-cognitive task performance. Int $\mathcal{F}$ Psychophysiol 1987; 5:97-106.

39 Leino PI, Hanninen V. Psychosocial factors at work in relation to back and limb disorders. Scand $\mathcal{f}$ Work Environ Health 1995;21:134-42.

40 Karasek RA. Job demands, job decision, job latitude, and mental strain: implications for job redesign. and mental strain: implications for job red

41 Ursin H, Endresen IM, Svebak S, Tellnes G, Mykletun R. Muscle pain and coping with working life in Norway: a review. Work and Stress 1993;7:247-58.

42 Ferguson $E$, Cox $T$, Farnsworth W, Irving $K$, Leiter $M$ Nurses anxieties about biohazards as a function of contex and knowledge. Fournal of Applied Social Psychology 1994;24:926-40.

43 Pawlikowska T, Chalder T, Hirsch SR, Wallace P, Wright DJM, Wesseley SC. Population based study of fatigue and psychological distress. BMF 1994;308:763-6.

44 Watson D, Clarke LA. Negative affectivity: the disposition to experience aversive emotional states. Psychol Bull 1994; 96:465-90.

45 Costa PT, McCrae RR. Neuroticism, somatic complaints and disease. Is the bark worse than the bite? $\mathcal{f}$ Pers 1987;55:299-316.

46 Watson D, Pennebaker JW. Health complaints, stress and distress: exploring the central role of negative affectivity Psychol Rev 1989;96:235-54.

47 McCrae RR. Controlling neuroticism in the measurement of stress. Stress Medicine 1990 6:237-41.

48 Moyle $P$. The role of negative affectivity in the stress process-tests of alternative models. Fournal of Organisational Behaviour 1995;16:647-68.

49 Rotter JB. Generalised expectancies for internal versus external control of reinforcement. Psychol Med Monogr Suppl 1966;80:1. (No 609).

50 Abella $R$, Heslin $R$. Health locus of control values and the behaviour of family and friends. An integrated approach to understanding preventative health behaviour. Basic and Applied Social Psychology 1984;5:283-93.

51 Lau RR. Origins of health locus of control beliefs. $\mathcal{f}$ Pers Soc Psychol 1982;42:322-34.

52 Wallston BS, Wallston KA. Locus of control and health: a review of the literature. Health Education Monographs 1978;6:107-17.

53 Kobasa SC, Maddi SR, Kahn S. Hardiness and health: a prospective study. F Pers Soc Psychol 1982;42:168-77.

54 Gekas V, Schwalbe ML. Beyond the looking glass self: social structure and efficacy-based self-esteem. Social Psychology Quarterly 1983;46:77-88.

55 Hale AR Subjective risk In: Singleton WT, Hovden JT, eds. Risks, concepts, and measures. New York: Wiley, 1986. 56 Cox T. Stress research and stress management: putting theory to work. Sudbury: HSE Books, 1993.

57 Baker GHB. Psychological factors and immunity [invited review]. F Psychosom Res 1987;31:1-10.

58 Morell MA, Sullaway ME, Helgesen VS. Stress in the work and home environments as related to ischemic heart disease risk factors. In: Green GM, Baker F, eds. Work, health, and productivity. New York: Oxford University Press, 1991.

59 Cooper C. Psychosocial stress and cancer. Chichester: Wiley, 1984.

60 Goldberg D, Williams P. A users guide to the General Health Questionnaire. London: NFER-Nelson, 1988.

61 Cox T, Thirlaway M, Gotts $G$, Cox S. The nature and assessment of general well-being. $\mathcal{F}$ Psychosom Res 1983; 27:353-9. 